\title{
Review: levomethadyl acetate hydrochloride improves retention in treatment and reduces heroin use in heroin dependence
}

Clark N, Lintzeris N, Gijsbers A, et al. LAAM maintenance vs methadone maintenance for heroin dependence. Cochrane Database Syst Rev 2002;(2):CD002210 (latest version Feb 5, 2002).

\section{QUESTION: In patients with heroin dependence, is levomethadyl acetate hydrochloride (LAAM) more effective than methadone for improving retention in treatment and reducing heroin use?}

\section{Data sources}

Studies were identified by searching Medline (January 1966 to August 2000), PsycINFO (1887 to August 2000), EMBASE/Excerpta Medica (January 1985 to August 2000), the Cochrane Controlled Trials Register (2000, Issue 2), College on Problems of Drug Dependence abstracts, and National Institute on Drug Abuse monographs. Bibliographies of relevant articles were reviewed and investigators in this field and the pharmaceutical industry were contacted for information on unpublished studies.

\section{Study selection}

Studies were selected if they were randomised controlled trials (RCTs), controlled clinical trials, or controlled prospective studies comparing LAAM maintenance with methadone maintenance for opioid dependence, and patients were heroin dependent or were receiving opioid replacement therapy for heroin dependence.

\section{Data extraction}

2 reviewers independently extracted data on sample size, study design, details of the intervention, study quality, and outcomes. Main outcomes included retention in treatment, reduction in opiate use, continuous abstinence from opiates, and global assessments of health.

\section{Main results}

15 RCTs met the selection criteria. Meta-analyses were done using random effects models where significant heterogeneity was detected. More patients allocated to LAAM than methadone had ceased their allocated medication by the end of the study period (10 RCTs, 1454 patients), but limited evidence showed that the groups did not differ for rates of dropout from all opioid substitution treatment (2 RCTs, 179 patients) (table). More patients in the methadone group than in the LAAM group failed to abstain from heroin use (5 RCTs, 983 patients) (table). In 1 RCT (110 patients), the percentage of urine tests negative for opiates of those collected (per person/wk) was lower in the LAAM group than the methadone group (weighted mean difference $-10,95$ CI -11.5 to $-8.5, \mathrm{p}<0.001)$. The groups did not differ for all cause mortality.

\section{Conclusion}

In patients with heroin dependence, levomethadyl acetate hydrochloride is more effective than methadone for reducing heroin use but retention in treatment may be better with methadone. Sources of funding:
State Government of
Victoria Community
Support Fund.

For correspondence: Dr N Clark, Turning Point Alcohol E Drug Centre, Fitzroy,

Victoria, Australia.

nicoc@turningpoint.org.au
Levomethadyl acetate hydrochloride (LAAM) v methadone for heroin dependence*

\begin{tabular}{|c|c|c|c|c|}
\hline \multirow{2}{*}{$\begin{array}{l}\text { Outcomes at } 13 \text { to } \\
52 \text { weeks }\end{array}$} & \multicolumn{2}{|c|}{ Weighted event rates } & \multirow[b]{2}{*}{ RRI $(95 \%$ Cl) } & \multirow[b]{2}{*}{ NNH (Cl) } \\
\hline & LAAM & Methadone & & \\
\hline $\begin{array}{l}\text { Cessation of allocated } \\
\text { medication }\end{array}$ & $52 \%$ & $39 \%$ & $36 \%$ (7 to 73$)$ & 8 (5 to 28$)$ \\
\hline $\begin{array}{l}\text { Cessation of all opioid } \\
\text { substitution treatment }\end{array}$ & $21 \%$ & $20 \%$ & $1 \%(-58$ to 76$)$ & Not significant \\
\hline & & & $\operatorname{RRR}(\mathrm{Cl})$ & NNT (Cl) \\
\hline Continued heroin use & $48 \%$ & $59 \%$ & $19 \%(9$ to 28$)$ & $9(6$ to 20$)$ \\
\hline
\end{tabular}

\section{COMMENTARY}

This excellent review by Clark et al has increased our knowledge about LAAM. It shows for the first time in a meta-analysis that LAAM is more effective than methadone at reducing concurrent heroin use (ie, at opiate stabilisation). This effect was observed despite higher dropout rates for LAAM than methadone, which may be related to the slower onset of opiate agonist effects on induction and the higher level of side effects with LAAM. The authors also point out that patients in the LAAM group could often access methadone treatment, whereas those in the methadone group typically could not access LAAM treatment when dropping out of the study, which would imply that patients in the methadone group would be more likely to be retained in the study.

LAAM (and its active metabolites) have an extremely long duration of action, meaning that the agonist effects do not fall off to the same extent as methadone before the next dose, and indeed that dosing with LAAM is required only every second or third day. This can be very useful in patients with opiate dependence who have failed to stabilise with methadone treatment (one third of patients find that methadone does not last them the full $24 \mathrm{~h}$ ), or in whom take home medication is not clinically indicated or is not permitted. The long duration of action also means that clinics need not open on weekends, the risk of diverting the medication (including child deaths) is reduced, and occupational activities are disrupted less. However, it may also mean that LAAM is less suitable for the more chaotic patients who require higher levels of psychological input. In addition, most patients prefer LAAM to methadone because of its smooth duration of action, "holding" better, and being associated with a milder withdrawal syndrome.

LAAM was approved for clinical use in America in 1994 and in Europe in 1997. However, LAAM was withdrawn in Europe 3.5 years later after 10 cases of serious cardiac arrhythmias associated with QT prolongation (7 cases), Torsade de pointes (4 cases), cardiac arrest (5 cases), and death (3 cases). In the US, where relatively few deaths have occurred, the Food and Drug Administration did not completely suspend LAAM, but recommended that it should not be used as a first line opiate pharmacotherapy.

The superior clinical effectiveness of LAAM over methadone, as shown by Clark $e t$ al, indicates that overcoming the safety issues relating to the cardiac side effects is necessary, so that LAAM can again be used in Europe. This may involve confining its use to both methadone and buprenorphine treatment failures, using electrocardiographic monitoring as the dose is increased, strongly counselling against the concurrent use of other drugs, and limiting its use to specialist centres.

Fegus Law, BSc, MBChB, MRCPsych University of Bristol, Bristol, UK 